\title{
EFFECT OF SEDATION WITH INTRAVENOUS INFUSION OF DEXMEDETOMIDINE AND FENTANYL DURING SURGERIES DONE UNDER REGIONAL ANAESTHESIA IN PAEDIATRIC PATIENTS
}

\author{
Nishtala Madhavi ${ }^{1}$, Bhargavi Sanket ${ }^{2}$
}

${ }^{1}$ Associate Professor, Department of Anaesthesiology, Indira Gandhi Institute of Child Health, Bangalore,India.

${ }^{2}$ Senior Resident, Department of Anaesthesiology, Indira Gandhi Institute of Child Health, Bangalore, India.

\begin{tabular}{l}
\hline ABSTRACT \\
BACKGROUND \\
In adults, extraperitoneal lower abdominal and lower limb procedures are performed under epidural or spinal anaesthesia without \\
supplemental general anaesthesia. However, similar procedures in paediatric population to be performed under regional \\
anaesthesia require additional sedation, analgesia to immobilise the child during institution of the regional anaesthetic technique \\
and continued sedation during the surgical procedure to ensure cooperation of the child. \\
Aims and Objectives- To evaluate the efficacy and safety of a combination of intravenous infusion of dexmedetomidine and fentanyl \\
for sedation during surgeries done under regional anaesthesia in children.
\end{tabular}

\section{MATERIALS AND METHODS}

22 children, ranging in age from 2 to 12 years of both sexes posted for lower limb deformity correction, lower abdominal, extraperitoneal and hypospadias repair were selected continuously for this study. Sample size since there were no previous similar studies, we selected continuously all patients who met the eligibility criteria during the study period. Pharmacological Interventions: Intravenous access was secured and the loading dose of intravenous Dexmedetomidine and Fentanyl, both at the rate of $1 \mathrm{ug} / \mathrm{kg} / \mathrm{hr}$ was infused over 10 minutes using a syringe pump. At the end of 10 minutes, a maintenance dose of $1 \mathrm{ug} / \mathrm{kg}$ of the same was continued. Lumbar epidural catheter was inserted using 19-G epidural Tuohy needle (PORTEX) and 0.5\% Bupivacaine $0.5 \mathrm{~mL} / \mathrm{kg}$ up to a maximum dose of $2.5 \mathrm{mg} / \mathrm{kg}$ was deposited and the catheter was secured. Surgical procedure was conducted with the child breathing spontaneously with supplementation of oxygen $3 \mathrm{~L} /$ minute through a face mask. Inj. Propofol $1 \mathrm{mg} / \mathrm{kg}$ was used as rescue sedation. The perioperative monitoring to evaluate the efficacy of sedation under the study regimen and need to opt for rescue sedation included ECG, Heart rate, NIBP, $\mathrm{SPO}_{2}$, $\mathrm{EtCO}_{2}$, the Respiratory rate, level of sedation and time to achieve Ramsay score of 2 in recovery room.

Design- Descriptive.

Setting- 250 bedded paediatric referral hospital offering tertiary care to South Asian population.

\section{RESULTS}

Effective sedation in all 22 patients was achieved intraoperatively with intravenous infusion of Fentanyl 1 ug/kg/hour and Dexmedetomidine $1 \mathrm{ug} / \mathrm{kg}$ /hour combined with epidural block with Bupivacaine $0.5 \%$. Primary outcome measured was the need for rescue sedation which was required in 3 out of 22 cases, i.e. 13.6\%. The vital parameters were as follows. The maximum change in mean heart rate from baseline was during the intraoperative period (P4), being $28.4 \pm 28.7$ ( $\mathrm{p}<0.001)$. The lowest recorded value was $58 / \mathrm{m}$. Blood pressure changes showed a maximum mean change from baseline seen in both the systolic as well as diastolic pressures at the end of 10 minutes of bolus and was $-7.7 \pm 18$ and $-7.8 \pm 16 \mathrm{mmHg}$. No patient's respiratory rate decreased to less than 12 breaths/min or increased above 28 breaths/min during the procedural sedation. The highest $\mathrm{EtCO}_{2}$ was $30 \mathrm{mmHg}$. Oxygen saturation remained between 97 to $100 \%$ during the study in all patients. The mean recovery time taken as a return to Ramsay sedation score of 2 or 3 was 15 minutes. Varying RR interval was seen in 3 cases (13.6\%).

\section{CONCLUSION}

A combination of fentanyl and dexmedetomidine infusion provides effective sedation during cases done under regional anaesthesia in infants and children with limited effects on cardiovascular and ventilatory function.

\section{KEY WORDS}

Dexmedetomidine, Fentanyl, Paediatric, Procedural Sedation, Regional Anaesthesia.

HOW TO CITE THIS ARTICLE: Madhavi N, Sanket B. Effect of sedation with intravenous infusion of dexmedetomidine and fentanyl during surgeries done under regional anaesthesia in paediatric patients. J. Evolution Med. Dent. Sci. 2018;7(22):2668-2670, DOI: $10.14260 /$ jemds $/ 2018 / 600$

'Financial or Other Competing Interest': None.

Submission 27-10-2017, Peer Review 19-11-2017,

Acceptance 22-11-2017, Published 28-05-2018.

Corresponding Author:

Dr. Nishtala Madhavi,

007 Aishwarya Bliss,

7th cross, Sarakki Main Road

JP Nagar, Phase 1, Bangalore, India.

E-mail:mnishtala@yahoo.com

DOI: $10.14260 /$ jemds $/ 2018 / 600$

(c) (i) $\ominus$

\section{BACKGROUND}

In adults, extraperitoneal lower abdominal and lower limb procedures are performed under epidural or spinal anaesthesia without supplemental general anaesthesia. However, similar procedures in paediatric population to be performed under regional anaesthesia require additional sedation, analgesia to immobilise the child during institution of the regional anaesthetic technique and continued sedation during the surgical procedure to ensure cooperation of the child. Thus, the characteristics of such a sedative-analgesic 
drug/ drug combination include provision of controllable depth of sedation and analgesia along with cardiorespiratory stability and easy reversibility. The suitable available agents include ketamine, midazolam, propofol, opioids or inhalational anaesthetics.(1) These drugs in combination or individually have drawbacks such as respiratory depression with or without need for airway support, haemodynamic changes or convulsions.(2)

Recently introduced alpha-1 selective agonist drug, dexmedetomidine ${ }^{(3)}$ has been tried as a sole agent for sedation in ICU and during non-invasive procedures like MRI.(4) However, for the painful procedural sedation, it has been used in combination with ketamine or midazolam effectively.(5) To provide sedation and analgesia during surgery under regional anaesthesia, a combination of dexmedetomidine with ketamine is given.(6)

The present prospective clinical study investigates the feasibility of achieving adequate sedation and analgesia with combined use of Dexmedetomidine and Fentanyl during conduct of epidural anaesthesia technique followed by surgery in children. The study also evaluates the occurrence of side effects and complications with the combined use of dexmedetomidine and fentanyl.

\section{MATERIALS AND METHODS}

After obtaining the Institutional Ethical Committee approval, 22 children of both sexes aged between 2 and 12 years undergoing extraperitoneal lower abdominal surgeries, hypospadias repair and lower limb orthopaedic procedures continuously were recruited under the study. Exclusion criteria included patients belonging to ASA III with cardiac abnormalities, coagulation disorders and those with severe spinal deformities. Written and informed consent was obtained from parents/guardians of the children included in the study. Preoperative sedation with oral midazolam syrup $0.5 \mathrm{mg} / \mathrm{kg}$ body weight was administered 30 minutes before the procedure.

In the operation theatre children were connected to ECG NIBP and Sp02. These children were induced with sevoflurane 6 vol\% in mixture of nitrous oxide and oxygen at a ratio of 50: 50. Intravenous access was secured under general anaesthesia and intravenous fentanyl $1 \mathrm{ug} / \mathrm{kg}$ was given and sevoflurane decreased to 2 vol\%. Dexmedetomidine bolus of $1 \mathrm{ug} / \mathrm{kg}$ was infused over 10 minutes using a syringe pump. At the end of ten minutes, the infusion was set to $1 \mathrm{ug} / \mathrm{kg}$ body weight/ hour as the maintenance dose. As the bolus of dexmedetomidine was started the child was positioned in the right lateral position and under aseptic precautions local skin infiltration with $2 \%$ lignocaine was done. Epidural catheter was inserted using a Tuohy needle in the lumbar epidural space and $0.5 \%$ bupivacaine in volume of $0.5 \mathrm{~mL} / \mathrm{kg}$ up to a maximum dose of $2.5 \mathrm{mg} / \mathrm{kg}$ was deposited and the catheter was secured. The child was turned supine and sevoflurane discontinued. Surgical procedure was conducted while the child was breathing spontaneously with supplementation of oxygen at $3 \mathrm{~L} /$ minute through a face mask. The sampling port of $\mathrm{EtCO}_{2}$ side stream monitor was fixed under the facemask at the nostril lip junction using adhesive plaster. Inj. Propofol $1 \mathrm{mg} / \mathrm{kg}$ was used as rescue sedation in case of movement, vocalisation by the child and conversion to general anaesthesia in case of non-cooperation by the children. Epidural bolus was repeated at 90 minutes with $0.5 \%$ bupivacaine, $0.25 \mathrm{~mL} / \mathrm{kg}$. Heart rate, systolic and diastolic $\mathrm{BP}, \mathrm{SPO}_{2}, \mathrm{EtCO}_{2}$ and respiratory rate was recorded at baseline after bolus drug administration at incision and then at 5-minute intervals till end of surgery. At 10 minutes before the conclusion of the procedure, the infusion of the drug was discontinued. After the surgical procedure, each child was transferred to the post anaesthesia care station and monitored for next two hours and vitals recorded every 30 minutes for 2 hours and then every 4 th hourly for 24 hours.

Haemodynamic and respiratory changes following administration of the study drugs as well as the epidural medication were compared with baseline values.

\section{RESULTS}

Study could be successfully completed in all the 22 cases. The mean age was $4.5 \pm 3.27$ years. The age distribution was as given in Table 1.

\begin{tabular}{|c|c|}
\hline Age (Years) & Number of Children \\
\hline 2 & 8 \\
\hline 3 & 1 \\
\hline 4 & 6 \\
\hline 5 & 3 \\
\hline 6 & 1 \\
\hline 7 & 0 \\
\hline 8 & 0 \\
\hline 9 & 0 \\
\hline 10 & 0 \\
\hline 11 & 0 \\
\hline 12 & 3 \\
\hline \multicolumn{2}{|c|}{ Table 1. Age Distribution } \\
\hline
\end{tabular}

The male-to-female ratio was 19 : 3 , as $59.09 \%$ of the cases were posted for hypospadias repair. The mean weight of the study group was $15.18 \mathrm{kgs}$. The surgeries done include hypospadias repair: 13 cases, lower limb orthopaedic surgeries: 6 cases and ureteric implantation: 3 cases. The average duration of the surgeries was 2 hours 16 minutes. Mean change in vitals at $\mathrm{P} 1$ (post induction) (10 minutes), $\mathrm{P} 3$ (post incision), P4 (average intraop), P5 (average postop) from baseline was recorded as '-': decrease from baseline; '+': increase from baseline.

\section{Statistical Analysis}

The outcome variables were used in the analyses without transformation. Mean change in the outcome values from baseline at each time point was calculated. Paired sample ttest was used to derive ' $p$ ' values for this change. A $p<0.05$ was considered statistically significant.

\begin{tabular}{|c|c|c|c|c|c|c|}
\hline Vitals & \begin{tabular}{|c|} 
Base- \\
line
\end{tabular} & P1 & P2 & P3 & P4 & P5 \\
\hline $\begin{array}{c}\text { HR } \\
(\mathrm{bpm})\end{array}$ & & $\begin{array}{c}-5.91 \\
(10.88) \\
{[0.02]}\end{array}$ & $\begin{array}{c}-18.18 \\
(13.83) \\
{[<0.001]}\end{array}$ & $\begin{array}{c}-20.77 \\
(17.65) \\
{[<0.001]}\end{array}$ & $\left.\begin{array}{c}-28.41 \\
(28.70) \\
{[<0.001]}\end{array}\right]$ & $\begin{array}{l}-22.05 \\
(23.08) \\
{[<0.001}\end{array}$ \\
\hline $\begin{array}{c}\text { SBP } \\
(\mathrm{mmHg})\end{array}$ & & $\begin{array}{c}-5.27 \\
(9.90) \\
{[0.021]} \\
\end{array}$ & $\begin{array}{c}-7.77 \\
(18.42) \\
{[0.061]}\end{array}$ & $\begin{array}{c}-3.18 \\
(18.86) \\
{[0.438]}\end{array}$ & $\begin{array}{c}-1.68 \\
(13.40) \\
{[0.56]}\end{array}$ & $\begin{array}{c}-0.32 \\
(13.36) \\
{[0.912]} \\
\end{array}$ \\
\hline $\begin{array}{c}\text { DBP } \\
(\mathrm{mmHg})\end{array}$ & & $\begin{array}{c}-3.9 \\
(14.3) \\
{[0.214]} \\
\end{array}$ & $\begin{array}{c}-7.82 \\
(16.68) \\
{[0.04]}\end{array}$ & $\begin{array}{c}-5.82 \\
(21.87) \\
{[0.23]}\end{array}$ & \begin{tabular}{|c|}
-2.64 \\
$(21.81)$ \\
{$[0.58]$}
\end{tabular} & $\begin{array}{c}-0.64 \\
(21.06) \\
{[0.89]}\end{array}$ \\
\hline $\begin{array}{c}\mathrm{RR} \\
\text { (per min) }\end{array}$ & & $\begin{array}{c}-1.09 \\
(4.78) \\
{[0.297]} \\
\end{array}$ & $\begin{array}{c}-2.0 \\
(4.70) \\
{[0.06]}\end{array}$ & $\begin{array}{c}-1.55 \\
(4.87) \\
{[0.151]}\end{array}$ & $\begin{array}{l}-0.73 \\
(5.99) \\
{[0.58]} \\
\end{array}$ & $\begin{array}{c}-1.95 \\
(6.67) \\
{[0.184]} \\
\end{array}$ \\
\hline $\mathrm{EtCO}_{2}$ & & & & & \begin{tabular}{|c|}
1.36 \\
$(4.75)$ \\
{$[0.192]$}
\end{tabular} & $\begin{array}{c}1.27 \\
(5.20) \\
{[0.264]}\end{array}$ \\
\hline$T c$ & & & & Iean & ), [P Valt & \\
\hline
\end{tabular}


The maximum change in mean heart rate from baseline was during the intraoperative period with the lowest recorded HR of $58 / \mathrm{bpm}$. This could be attributed to the peak action of the study drug infusion combined with the effects of regional blockade.

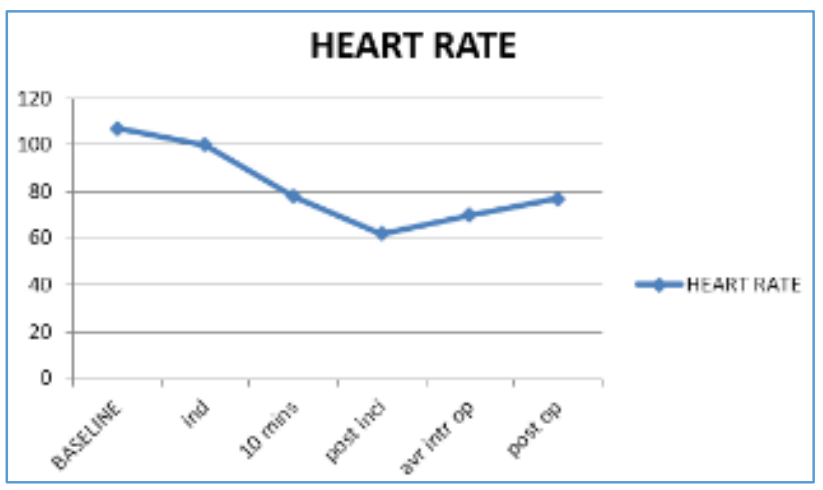

Blood pressure- The maximum mean change from baseline was seen in both the systolic as well as diastolic pressures at the end of the 10 minutes of bolus. However, at no point in the study time was there a significant change in the mean systolic.

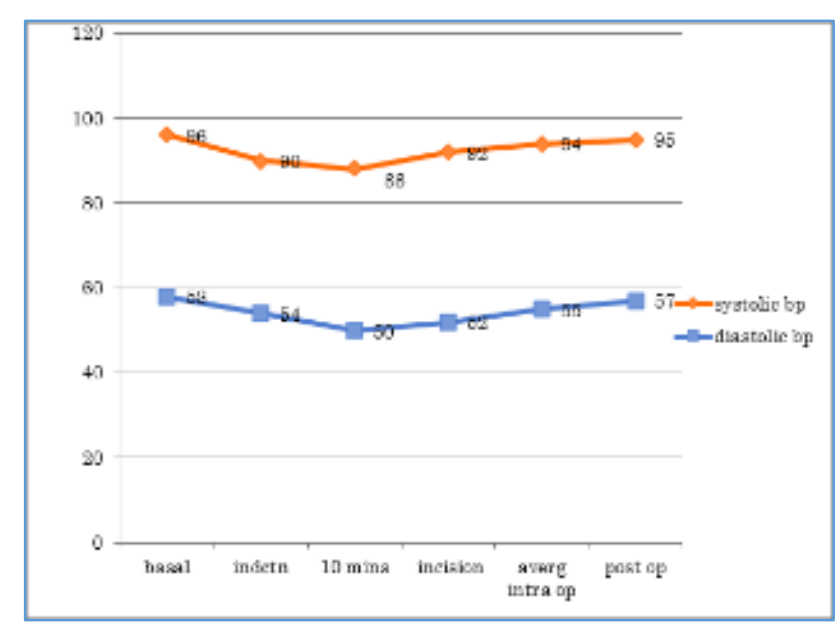

There was no significant change in respiratory rate, end tidal carbon dioxide from the baseline at any point of time.

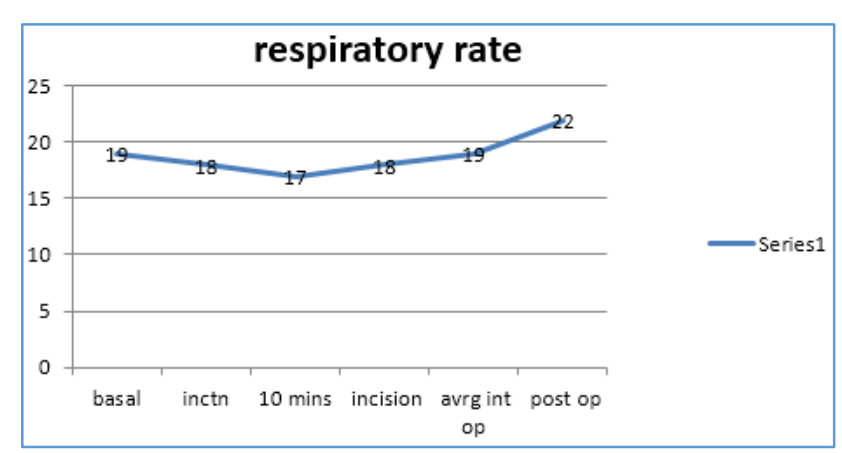

The mean recovery time taken to Ramsay sedation score of 2 or 3 was 15 minutes.

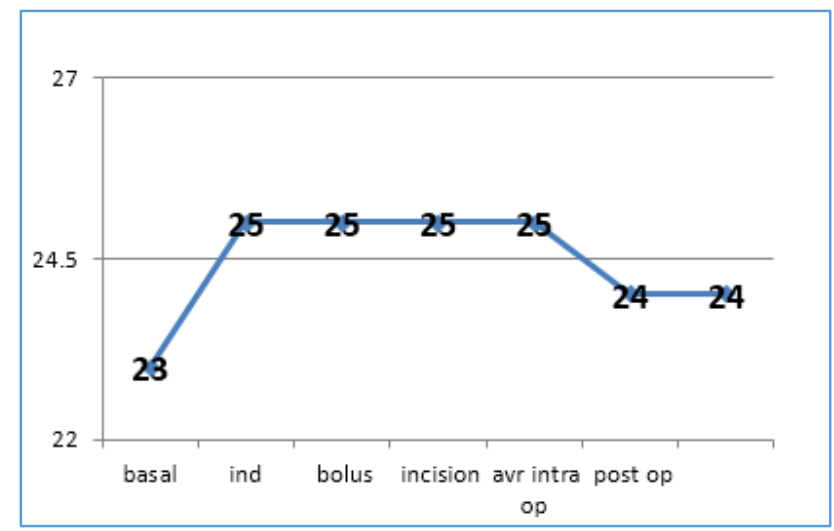

Rescue sedation with propofol was required in 3 out of 22 cases, i.e. $13.6 \%$. No cases were converted to general anaesthesia. Varying RR interval was seen in 3 cases (13.6\%), which reverted to normal without any intervention.

\section{DISCUSSION}

We based our study on a prospective study by McVey, Tobias who evaluated the combination of dexmedetomidine and Ketamine for sedation during lumbar puncture and sedation for spinal anaesthesia in children. Bolus dose of ketamine (2 $\mathrm{mg} / \mathrm{kg}$ ) and dexmedetomidine $(1 \mu \mathrm{g} / \mathrm{kg})$ were given over three minutes followed by a continuous infusion of dexmedetomidine $(2 \mu \mathrm{g} / \mathrm{kg} / \mathrm{hr}$ for the first 30 mins followed by $1 \mu \mathrm{g} / \mathrm{kg} / \mathrm{hr}$ for the duration of the case). Supplemental analgesia/ sedation was with ketamine. Effective sedation was achieved with limited effect on cardiovascular and respiratory function.

\section{CONCLUSION}

Dexmedetomidine fentanyl infusion in the dosage used in this study is an excellent sedative to complement epidural regional anaesthesia in children. Its use allows paediatric surgeries to be done under epidural anaesthesia, thereby avoiding general anaesthesia and associated polypharmacy, airway manipulation. It is safe, associated with stable haemodynamics without respiratory compromise, fast and smooth recovery.

\section{REFERENCES}

[1] Cravero JP, Havidich JE. Pediatric sedation-evolution and revolution. Paediatr Anaesth 2011;21(7):800-9.

[2] Mason KP, O'Mahony E, Zurakowski D, et al. Effects of dexmedetomidine sedation on the EEG in children. Paediatr Anaest 2009;19(12):1175-83.

[3] Roberts TL. Dexmedetomidine-pharmacotherapy perspective. Journal of the Pharmacy Society of Wisconsin 2003:47-52.

[4] Mason KP, Lubisch NB, Robinson F, et al. Intramuscular dexmedetomidine sedation for pediatric MRI and CT AJR Am J Roentgenol 2011;197(3):720-5.

[5] Godambe SA, Elliot V, Matheny D, et al. Comparison of propofol/fentanyl versus ketamine/midazolam for brief orthopedic procedural sedation in a pediatric emergency department. Pediatrics 2003;112(1 Pt 1):116-23.

[6] McVey JD, Tobias JD. Dexmedetomidine and ketamine for sedation during spinal anaesthesia in children. J Clin Anaesth 2010;22(7):538-45. 